\title{
Recent Thymic Emigrants Do Not Account for the Increased Number of T- Cells Seen in the Lungs of Stable Chronic Obstructive Pulmonary Disease
}

\author{
Gaetano Caramori $^{*}{ }^{\S, 1}$, Kazuhiro Ito $^{\S, 2}$, Elen Jazrawi ${ }^{2}$, Paolo Casolari ${ }^{1}$, Kian Fan Chung ${ }^{2}$, \\ Peter J. Barnes ${ }^{2}$, Ian M. Adcock ${ }^{\S, 2}$ and Alberto Papi ${ }^{\S, 1}$ \\ ${ }^{1}$ Centro di Ricerca su Asma e BPCO, Università di Ferrara, Ferrara, Italy \\ ${ }^{2}$ Airway Disease Section, NHLI, Imperial College London, UK
}

\begin{abstract}
Chronic obstructive pulmonary disease (COPD) patients have an increased number of $\mathrm{T}$ cells within their lungs. It is unknown whether these $T$ cells, remain there forever or if there is a continuous turnover from the blood. In the adult, there is a significant $\mathrm{T}$ lymphocytopoiesis from the thymus producing cells known as recent thymic emigrants (RTEs). T cell receptor excision circles (TREC) are a marker of RTEs. We investigated the number of TREC in blood from patients with untreated stable, mild to moderate COPD $(n=6)$ compared with age-matched smokers with normal lung function $(n=6)$ and nonsmokers $(n=8)$. The results showed variable expression of TREC in each subject group and no significant difference between TREC expressions in any group of subjects. Changes in T-cell numbers in the lung of stable COPD patients may reflect prolonged survival or proliferation of these cells within the lung rather than continuous recruitment from the blood.
\end{abstract}

Keywords: Recent thymic emigrants, TREC, T lymphocytes, COPD.

\section{INTRODUCTION}

Chronic obstructive pulmonary disease (COPD) is currently a leading cause of morbidity and mortality worldwide [1]. The main cause of COPD is cigarette smoking [1]. Chronic airflow obstruction in COPD is caused by small (peripheral) airway lesions, including a $\mathrm{T}$ lymphocytes rich inflammation [2]. The number of T lymphocytes in the lungs of COPD patients is increased compared to smokers with normal lung function and non-smokers [3]. It is still unknown if the $\mathrm{T}$ lymphocytes remain forever in the lungs of the COPD patients of if there is a continuous turnover from the blood T lymphocytes. In fact, many studies have shown that, in the adult, there is still a significant $\mathrm{T}$ lymphocytopoiesis from the thymus $[4,5]$. Using a real-time PCR assay it is possible to measure in the peripheral venous blood the number of $\mathrm{T}$ lymphocytes that are just produced from the thymus, they are known with the acronym "recent thymic emigrants" (or T-cell-receptor rearrangement excision DNA circles; TREC). In normal subjects, peripheral TREC levels are a good reflection of thymic function as demonstrated by their correlation with intrathymic TREC values [6]. The aim of our study was to investigate if the total number of peripheral venous blood recent thymic emigrants (TREC) is different in smokers with steroid naïve mild to moderate stable COPD compared to control groups of age-matched smokers with normal lung function and age-matched lifelong asymptomatic non-smokers.

*Address correspondence to this author at the Centro di Ricerca su Asma e BPCO, Università di Ferrara, Via Savonarola 9, 44100 Ferrara, Italy;

Tel: +39-0532-210420; Fax: +39-0532-210297;

E-mail: gaetano.caramori@unife.it

${ }^{\S}$ These authors contributed equally to this work.

\section{MATERIALS AND METHODOLOGY}

\section{Subjects}

All subjects were recruited from the Section of Respiratory Medicine of the University Hospital of Ferrara, Italy. We recruited twenty subjects. Eight subjects were asymptomatic lifelong non smokers with normal lung function. Six were "healthy" smokers with normal lung function and six subjects were smokers with mild to moderate COPD in stable phase (Table 1).

All former smokers had stopped smoking for more than one year prior to study commencement. COPD was defined, according to international guidelines, as the presence of postbronchodilator $\mathrm{FEV}_{1} / \mathrm{FVC}$ ratio $<70 \%$ [1]. All subjects were free from chest symptoms by at least 3 months. None of the subjects have been treated with anticholinergics, theophylline, antioxidants and/or glucocorticoids or other immunomodulatory drugs, chemo/radiotherapy at any time.

Before peripheral venous blood sampling each patient has been interviewed and lung function and chest radiography have been performed as previously described [7]. Pulmonary function tests were performed as previously described [8] according to published guidelines. Predicted values for the different measures were calculated from the regression equations published by Quanjer [9]. Our study was part of a project that examined the molecular mechanisms of inflammation in COPD and it was approved by the local ethics committee of the University Hospital of Ferrara, and informed consent was obtained from each participant in accordance with the principles outlined in the Declaration of Helsinki.

\section{Peripheral Blood Mononuclear Cells Isolation}

Peripheral blood mononuclear cells (PBMCs) isolation was performed as previously described [10]. Briefly, venous 
Table 1. Subject Characterization

\begin{tabular}{|c|c|c|c|c|c|c|c|}
\hline Subjects & $\mathbf{n}$ & Age & Sex & Smoking History & Pack-Years & FEV $\%$ Pred & FEV $\mathbf{1}$ FVC\% \\
\hline \hline Nonsmokers & 8 & $58.1 \pm 2.7$ & $5 \mathrm{M} / 3 \mathrm{~F}$ & all non smokers & 0 & $108.1 \pm 7.5$ & $81.4 \pm 1.4$ \\
\hline "Healthy" Smokers & 6 & $53 \pm 3.7$ & $5 \mathrm{M} / 1 \mathrm{~F}$ & all current smokers & $23.7 \pm 4$ & $111.8 \pm 7.5$ & $79.3 \pm 3.3$ \\
\hline COPD & 6 & $65.5 \pm 2.6$ & $6 \mathrm{M}$ & $\begin{array}{c}3 \text { Ex smokers } \\
\text { current smokers }\end{array}$ & $59 \pm 16.4$ & $74.3 \pm 11.2 *$ & $61.3 \pm 3.8^{*}$ \\
\hline
\end{tabular}

Abbreviations: COPD=chronic obstructive pulmonary disease; M: Male; F: Female; $\mathrm{FEV}_{1}=$ forced expiratory volume in one second; FVC=forced vital capacity. For COPD and "healthy" smokers with normal lung function subjects $\mathrm{FEV}_{1} \%$ pred and $\mathrm{FEV}_{1} / \mathrm{FVC} \%$ are post-bronchodilator values. Data expressed as mean \pm standard error of the mean (SEM); *p $<0.05 v s$ "healthy" smokers.

blood $(80 \mathrm{ml})$ was diluted 1:1 with Hanks' buffered saline solution and layered on Ficoll-Hypaque-Plus (Amersham plc, Buckinghamshire, UK). After centrifugation (30 min at $1,100 \times g$ and $18^{\circ} \mathrm{C}$ ), PBMCs were collected, washed, and centrifuged $(250 \times \mathrm{g}$ for $10 \mathrm{~min})$. The dry cell pellet was immediately frozen in liquid nitrogen and stored at $-80^{\circ} \mathrm{C}$ before genomic DNA extraction.

\section{Genomic DNA Extraction}

Genomic DNA was isolated exactly as previously described [11] using a Dneasy tissue kit (Qiagen, Crawley, UK).

\section{Measurement of the Number of TREC Using the Real- Time PCR Assay}

Taqman-based real time PCR (RT-QPCR) analysis was performed on PBMCs with TREC specific primers to detect recent thymic emigrants, and on CCR5 coding sequence to standardize for DNA content exactly as described elsewhere [5]. According to Hatzakis et al. in each genomic DNA sample, PBMCs were quantified as one cell per two CCR5 copies and the TREC number was expressed as the number of TREC per $10^{6}$ PBMCs.

The sequence of the human TREC-specific Taqman detection probe was FAM-5'-CTGCTCTTCACCGTTCTCTAMRA-3' (250nM), and the sequences of the PCR primers were forward 5'-GATGGAAAACACAGTGTGACATGG-3' $(50 \mathrm{nM})$ and reverse 5'-CTGTCAACAAAGGTGATGCCAC AT-3' (50nM). The sequence of the human CCR5-specific Taqman detection probe was FAM-5'-ATGACAAGCAGCG GAGG-TAMRA-3' (175nM) and the sequences of the PCR primers were forward 5'-GCTGTGTTTGCGTCTCTCCCAG GA-3' (300nM) and reverse 5'-CTCACAGCCCTGTGCCTC TTCTTC-3' (900nM). One microgram of genomic DNA, $0.25 \mu \mathrm{mol} / 1$ of Taqman probe and $0.5 \mu \mathrm{mol} / \mathrm{l}$ of each primer were added to the master mix (Taqman Universal Mix, Applied Biosystems, Warrington, UK). FAM signals in 50 cycles of amplification (Hold $50^{\circ} \mathrm{C}$ for $2 \mathrm{~min}, 95^{\circ} \mathrm{C}$ for 10 min and then 50 cycles at $95^{\circ} \mathrm{C}$ denaturation for $15 \mathrm{~s}$ and at $60^{\circ} \mathrm{C}$ for $60 \mathrm{~s}$ ) were detected on a Rotor-Gene 3000 (Corbett Research, Mortlake, NSW, Australia). After completion of the PCR amplification, each thresold (dT) was measured and the ratio of TREC copy number and CCR5 gene copy number (x2) were determined by known concentrations of initial DNA templates. The amount of TREC per 100ng of DNA was also determined on the basis of the standard curve, with a lower limit of detection of 3 copies/100ng of genomic DNA.

\section{Statistical Analysis}

Group data were expressed as mean and standard error (SEM) and differences between groups determined by nonparametric ANOVA. Post-test analysis was performed using the Mann-Whitney U test. A probability value of $<0.05$ was considered significant.

\section{RESULTS}

\section{Clinical Parameters}

Clinical parameters and pulmonary function of the patients are summarized in Table 1. The three groups of subjects were similar with regard to age and gender and there was no significant difference in the smoking history (packyears) between COPD and smokers with normal lung function. As expected from the selection criteria, smokers with COPD had a significantly lower forced expiratory volume in one second $\left(\mathrm{FEV}_{1}\right)$ and $\mathrm{FEV}_{1} / \mathrm{FVC}$ ratio as compared to control smokers with normal lung function and non-smokers.

\section{TREC Number in the Peripheral Venous Blood}

The results showed variable expression of TREC in each subject group. Although there was a tendency towards increased expression in smokers and COPD (43.5 \pm 14.8 vs $153.7 \pm 98.2$ vs $130.4 \pm 54.4$ TREC/CCR5 in $\left.\times 10^{6} \mathrm{PBMCs}\right)$ there was no significant difference between TREC expression in any group of subjects whether expressed per 100ng DNA or in relation to CCR5 (Fig. 1). In addition, there was no effect of active smoking on TREC expression.

\section{DISCUSSION}

In this study, we report for the first time the number of TREC in peripheral venous blood from patients with mild to moderate stable COPD and age-matched non-smokers and smokers with normal lung function (control groups). Pathological studies have demonstrated that the chronic inflammatory response in COPD is rich in $\mathrm{T}$ lymphocytes in both small (peripheral) and central airways $[1,3]$. It is unknown if these $T$ cells are retained in the lungs of the COPD patients for prolonged times or if there is a continuous turnover from the blood T cells. A change of the number of peripheral venous blood recent thymic emigrants has been described during the physiological process of aging [6], in workers exposed to benzene [12] and in many pathological conditions [4, 5, 13-20]. However, interestingly to the best of our knowledge there is a complete absence of published studies on changes of TREC numbers in inflammatory or neoplastic diseases of the lung. 
(A)

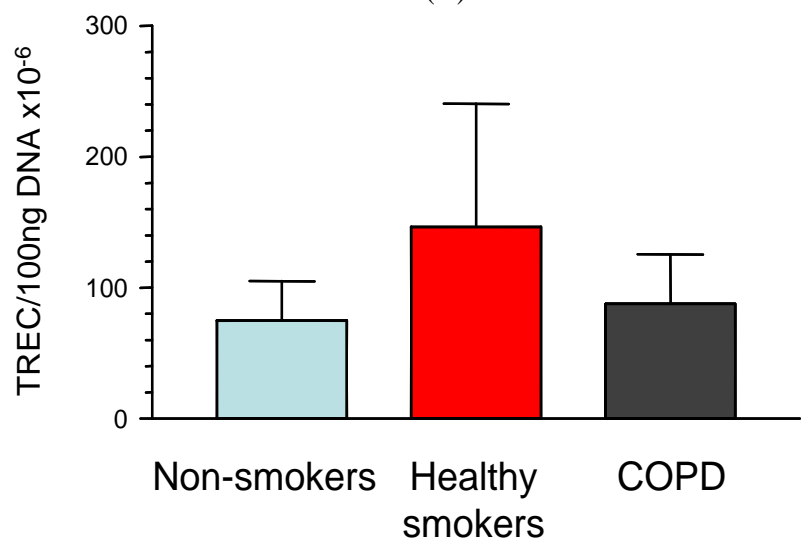

(B)

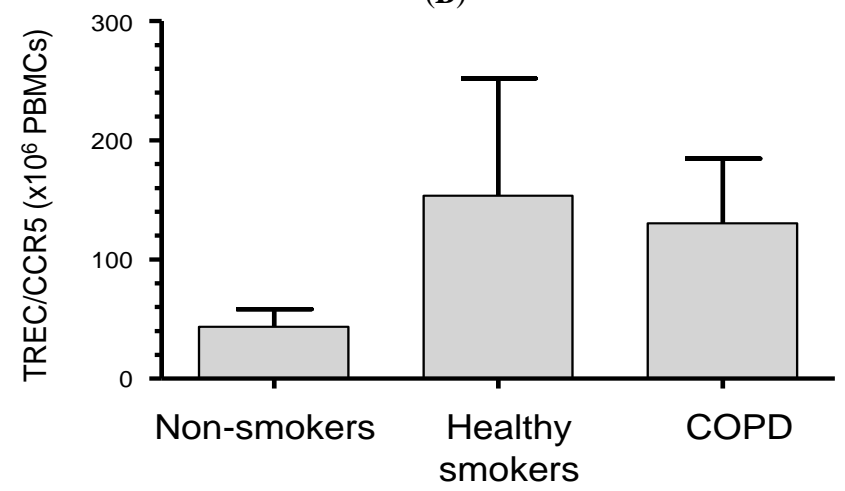

Fig. (1). Expression of TREC within peripheral blood Tlymphocytes of age-matched non-smokers, healthy smokers with normal lung function and smokers with COPD. TREC were detected by RT-QPCR and quantified according to DNA content (A) and CCR5 in $\times 10^{6}$ PBMCs (B). Peripheral venous blood was obtained from 8 non-smokers, 6 healthy smokers with normal lung function and 6 smokers with COPD.

We have demonstrated for the first time that the number of recent thymic emigrants is variable and not significantly different in the peripheral venous blood of patients with untreated stable mild to moderate COPD compared both with age-matched smokers with normal lung function and nonsmokers (control groups) despite the previously described differences in peripheral blood and bronchoalveolar lavage (BAL) T-cell phenotypes observed in these subjects [21-27].

This data suggests that prolonged survival rather than recruitment to the airways occurs in COPD. Although bronchus-associated lymphoid tissue (BALT) is completely absent in the lung of normal adults it is induced in presence of chronic inflammatory diseases, such as rheumatoid arthritis [28] and severe and very severe (Global Initiative for Chronic Obstructive Lung Disease stage 3 and 4) COPD [2], suggesting that in the presence of an intense chronic inflammatory stimulation lymphoid cells may proliferate locally. In addition, also in animal models of chronic inflammation, there is local lymphoid neogenesis [29]. Our data provides indirect evidence for a lack of T-cell recruitment to the airways and this hypothesis will drive future studies in this area.

\section{CONCLUSIONS}

In conclusion our data provides indirect evidence suggesting as a hypothesis for future study that changes in T-cell numbers in the lungs of untreated mild to moderate COPD patients in stable phase, compared with age-matched smokers with normal lung function and non-smokers, may reflect prolonged survival of these cells within the lung rather than continuous recruitment from the blood.

\section{ACKNOWLEDGEMENT}

This work was supported by Associazione per la Ricerca e la Cura dell' Asma (ARCA, Padova, Italy).

\section{REFERENCES}

[1] Global Initiative for Chronic Obstructive Lung Disease. Global Strategy for the Diagnosis, Management and Prevention of Chronic Obstructive Pulmonary Disease. NHLBI/WHO workshop report. Bethesda, National Heart, Lung and Blood Institute, April 2001; NIH Publication No 2701: 1-100. Last update 2007. http://www. goldcopd.com (accessibility verified July 2, 2008).

[2] Hogg JC, Chu F, Utokaparch S, et al. The nature of small-airway obstruction in chronic obstructive pulmonary disease. N Engl J Med 2004; 350: 2645-53.

[3] Baraldo S, Lokar Oliani K, Turato G, Zuin R, Saetta M. The role of lymphocytes in the pathogenesis of asthma and COPD. Curr Med Chem 2007; 14: 2250-56.

[4] Douek DC, McFarland RD, Keiser PH, et al. Changes in thymic function with age and during the treatment of HIV infection. Nature 1998; 396: 690-95.

[5] Hatzakis A, Touloumi G, Karanicolas R, et al. Effect of recent thymic emigrants on progression of HIV-1 disease. Lancet 2000; 355: 599-604.

[6] Arellano MV, Ordonez A, Ruiz-Mateos E, et al. Thymic functionrelated markers within the thymus and peripheral blood: Are they comparable? J Clin Immunol 2006; 26: 96-100.

[7] Varani K, Caramori G, Vincenzi F, et al. Alteration of adenosine receptors in patients with chronic obstructive pulmonary disease. Am J Respir Crit Care Med 2006; 173: 398-406.

[8] Ito K, Ito M, Elliott WM, et al. Decreased histone deacetylase activity in chronic obstructive pulmonary disease: relationship to disease severity. N Engl J Med 2005; 352: 1967-1976.

[9] Quanjer P, Tammeling GJ, Cotes JE, Pedersen OF, Peslin R, Yernault JC. Lung volumes and forced ventilatory flows. Report Working Party, standardization of lung function tests, European Community for Steel and Coal, official statement of the European Respiratory Society. Eur Respir J 1993; 6: 5-40.

[10] Hew M, Bhavsar P, Torrego A, et al. Relative corticosteroid insensitivity of peripheral blood mononuclear cells in severe asthma. Am J Respir Crit Care Med 2006; 174: 134-41.

[11] Pulleyn LJ, Newton R, Adcock IM, Barnes PJ. TGF $\beta_{1}$ allele association with asthma severity. Hum Genet 2001; 109: 623-27.

[12] Lan Q, Zhang L, Hakim F, et al. Lymphocyte toxicity and T cell receptor excision circles in workers exposed to benzene. Chem Biol Interact 2005; 153-154: 111-115.

[13] Madhok AB, Chandrasekran A, Parnell V, Gandhi M, Chowdhury $\mathrm{D}$, Pahwa S. Levels of recent thymic emigrant cells decrease in children undergoing partial thymectomy during cardiac surgery. Clin Diagn Lab Immunol 2005; 12: 563-65.

[14] Prada N, Nasi M, Troiano L, et al. Direct analysis of thymic function in children with Down's syndrome. Immun Ageing 2005; 2: 411.

[15] Cianci R, Pinti M, Nasi M, et al. Impairment of recent thymic emigrants in HCV infection. Int J Immunopathol Pharmacol 2005; 18: 723-28.

[16] Kayser C, Alberto FL, da Silva NP, Andrade LE. Decreased number of T cells bearing TCR rearrangement excision circles (TREC) in active recent onset systemic lupus erythematosus. Lupus 2004; 13: 906-11. 
[17] Thewissen M, Linsen L, Somers V, Geusens P, Raus J, Stinissen P. Premature immunosenescence in rheumatoid arthritis and multiple sclerosis patients. Ann NY Acad Sci 2005; 1051: 255-62.

[18] Sutherland JS, Goldberg GL, Hammett MV, et al. Activation of thymic regeneration in mice and humans following androgen blockade. J Immunol 2005; 175: 2741-53.

[19] Kuss I, Schaefer C, Godfrey TE, et al. Recent thymic emigrants and subsets of naive and memory $\mathrm{T}$ cells in the circulation of patients with head and neck cancer. Clin Immunol 2005; 116: 27-36.

[20] Yamanaka K, Yawalkar N, Jones DA, et al. Decreased T-cell receptor excision circles in cutaneous T-cell lymphoma. Clin Cancer Res 2005; 11: 5748-55.

[21] Kim WD, Kim WS, Koh Y, et al. Abnormal peripheral blood Tlymphocyte subsets in a subgroup of patients with COPD. Chest 2002; 122: 437-44.

[22] Gupta J, Chattopadhaya D, Badhoria DP, et al. T lymphocyte subset profile and serum alpha-1-antitrypsin in pathogenesis of chronic obstructive pulmonary disease. Clin Exp Immunol 2007; 149: 46369.
[23]

Koch A, Gaczkowski M, Sturton G, et al. Modification of surface antigens in blood $\mathrm{CD}^{+} \mathrm{T}$-lymphocytes in COPD: effects of smoking. Eur Respir J 2007; 29: 42-50.

[24] Glader P, von Wachenfeldt K, Lofdahl CG. Systemic CD4 ${ }^{+}$T-cell activation is correlated with FEV1 in smokers. Respir Med 2006; 100: 1088-93.

[25] Domagala-Kulawik J, Hoser G, Dabrowska M, Chazan R. Increased proportion of Fas positive $\mathrm{CD}^{+}$cells in peripheral blood of patients with COPD. Respir Med 2007; 101: 1338-43.

[26] Barczyk A, Pierzchala W, Kon OM, Cosio B, Adcock IM, Barnes PJ. Cytokine production by bronchoalveolar lavage T lymphocytes in chronic obstructive pulmonary disease. J Allergy Clin Immunol 2006; 117: 1484-92.

[27] Smyth LJ, Starkey C, Vestbo J, Singh D. CD4-regulatory cells in COPD patients. Chest 2007; 132: 156-63.

[28] Rangel-Moreno J, Hartson L, Navarro C, Gaxiola M, Selman M, Randall TD. Inducible bronchus-associated lymphoid tissue (iBALT) in patients with pulmonary complications of rheumatoid arthritis. J Clin Invest 2006; 116: 3183-94.

[29] Aloisi F, Pujol-Borrell R. Lymphoid neogenesis in chronic inflammatory diseases. Nat Rev Immunol 2006; 6: 205-17.

(C) Caramori et al.; Licensee Bentham Open.

This is an open access article licensed under the terms of the Creative Commons Attribution Non-Commercial License (http://creativecommons.org/licenses/by$\mathrm{nc} / 3.0 /$ ) which permits unrestricted, non-commercial use, distribution and reproduction in any medium, provided the work is properly cited. 